Häufigkeit der vorzeitigen Untexbrechung der Schwangerschaft, Centralbl. f. Gynäk., 1895, p. 1348. Lechler, E.: Pathologie und Therapie des Abortus, Inaug. Dissert., Berlin, 1883, Malins, Edward: Some Aspects of the Economic and of the Antenatal Waste of Life in Nature and Civilization, Jour. Obst. and Gynec. Brit. Emp., 1903, iii. Mall, F. P.: On the Frequency of Localized Anomalies in Human Embryos and Infants at Birth, Am. Jour. Anat., 1917, xxii, ibid.: Note on. Abortions with Letters from the Health Commissioner of Baltimore and from the Chief of the Bureau of Vital Statisties of Maryland Regarding Registration and Shipment of Embryos to the Carnegie Laboratory of Embryology at the Johns Hopkins Medical School, Circular No. 20, January 20, 1917. Michailoff: Durchschnittszifferm der Geburtshïlfe in Russland in 50 Tahren, Jour. f. Geburtsh., 1897, p. 859, (Russian). Pearson, Cairl: The Chances of Death, London, 1906. Robinson, Wm. J.: Abortion, Historically and Ethnologically Considered, Am. Jour. of Urology and Sexology, 1919, xv. Schultz, Adolph: Chapter vii in Studies on Abortuses: A Survey of and Studies upon Pathological Ova in the Carnegie Embryological Collection, Mall-Meyer, Carnegie Institution, Washington, D. C., 1921. Solowij, A.: Uber Bösartigkeit der. Blascumole, Verhandl. d. dentseh. Gesellsch. f. Gynäk., Achte Versammlung, 1899. Stumpf, Max: Tur Ätiologie und Rehandling der Fehl- and Frülngeburten, München, med. Wehnschr., 1892, xl. Taussig, F. J.: Prevention and Treatment of Abortion, St. Louis, 1910. Williams, J. Whitridge: Text-book of Obstetrics, New York and London, 1916.

121 WAVERLY STREET.

\title{
SPONTANEOUS EVOLUTION FOLLOWING TRANSVERSE PRESENTATION OF THE FETUS
}

\section{With Report ofn a Case}

\author{
By Matrhew Marshall, B.S., M.D., Pittsburgh, Pa.* \\ From the Department of Obstetrics, (Service of Dr. Paul Titus), Western Penn- \\ sylvanic LIospital, Pittsburgh.
}

$\mathrm{T}$ RANSVERSE presentation of the fetus is a formidable complication, especially if the patient has been allowed to advance in her labor to the point where the arm has prolapsed and the shoulder has become impacted into the pelvis. In practically all such cases it will be found that the fetus is dead and unless proper treatment is instituted promptly there is grave danger of rupture of the thinned-out lower uterine segment of the uterus.

Decapitation of the dead fetus is, quite naturally, the first procedure considered when one is confronted by such a situation and as a general thing some such operation must be undertaken at once. Oceasionally, however, spontaneous evolution may occur, and is of interest, not because it offers an outlook for delivery in a neglected ease, but because of its extreme rarity.

Spontaneous evolution is a mechanism of delivery by which the body of the transversely presenting fetus is bent upon itself, being forced gradually down into the pelvis. The head impinges above the ileopectineal line on one side, and the neck becomes excessively stretched, thus allowing the shoulder, arm and thorax to be packed

*Posthumous publication, Dr. Miarshall's death having occurred on January 24, 1921. 
down into the birth canal. Prolapse of the arm gains room for the trunk and eventually the groin, the buttocks appear next at the vulva alongside the arm, whereupon evolution is complete and delivery may be effected with comparative ease.

Spontaneous evolution is not to be confused with spontaneous version. This latter is simply the spontaneous conversion of a transverse presentation into a longitudinal one by virtue of the fact that the fetus is more or less freely movable in the fluid contained within an

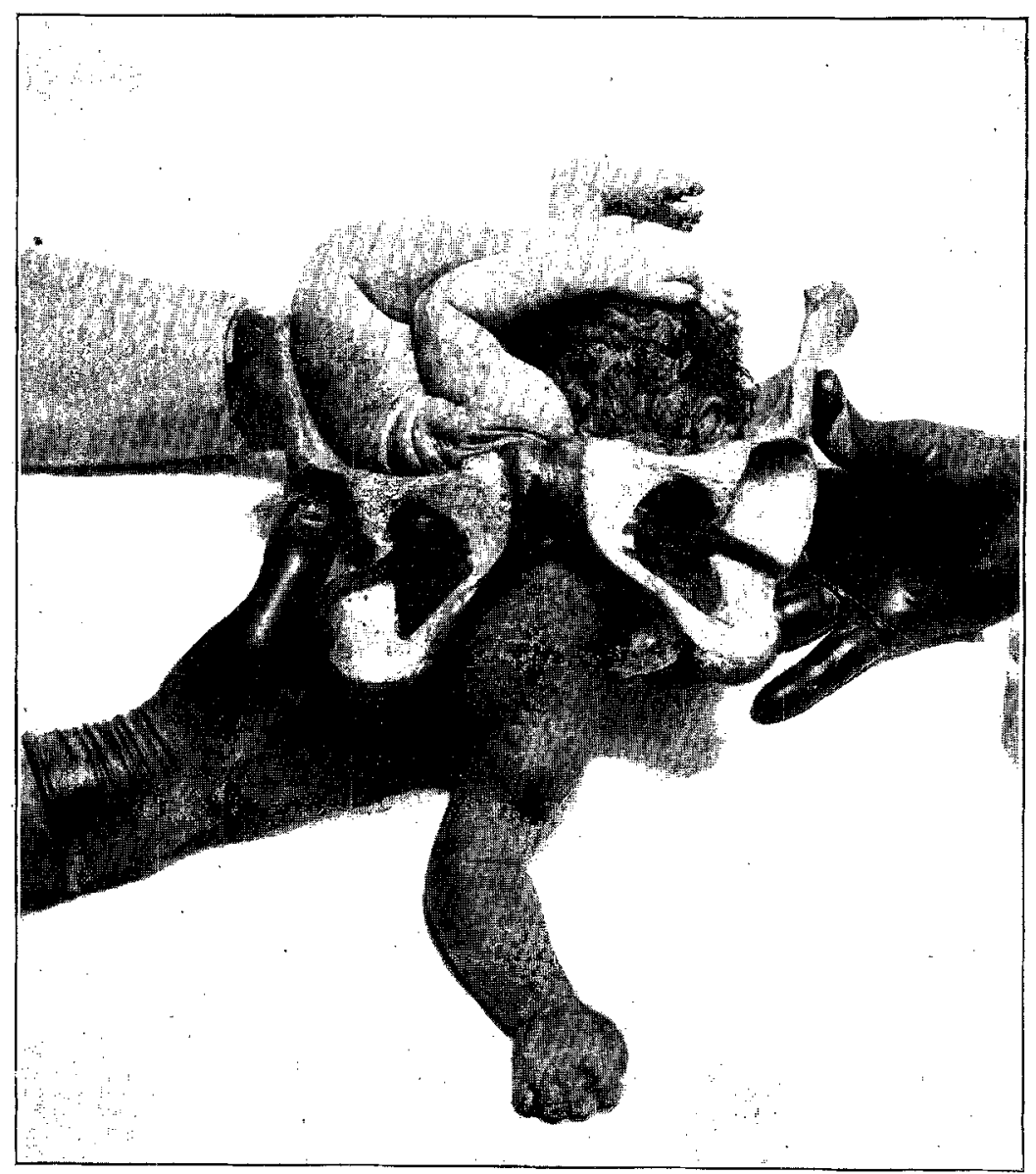

Fig. 1.-First step in Douglas' mechanism of spontaneous evolution: impaction of shoulder with prolapse of arrn.

intact amniotic sac. This may be brought about by the occurrence of labor pains or even by changes in posture, and is mentioned merely to emphasize the distinction between the comparatively common thing on the one hand and the rare condition on the other.

\section{HISTORICAL REVIEW OF CASES AND MECHANISMS DESCRIBED}

Considerable confusion seems to exist in the minds of those who have been interested in these conditions, because of the distinetion between 
the three conditions, (1) spontaneous version, (2) partus con duplicato corpore, in which the head and thorax pass through the birth canal simultancously, the head having been sharply flexcd upon and pressed into the thorax, and (3) spontaneous evolution as described above.

Hippocrates recognized transverse presentations, and according to his ideas the prolapse of an arm was an indication of fetal death. Payer ${ }^{\mathrm{I}}$ says that Hippocrates considered the possibility of spontaneous evolution.

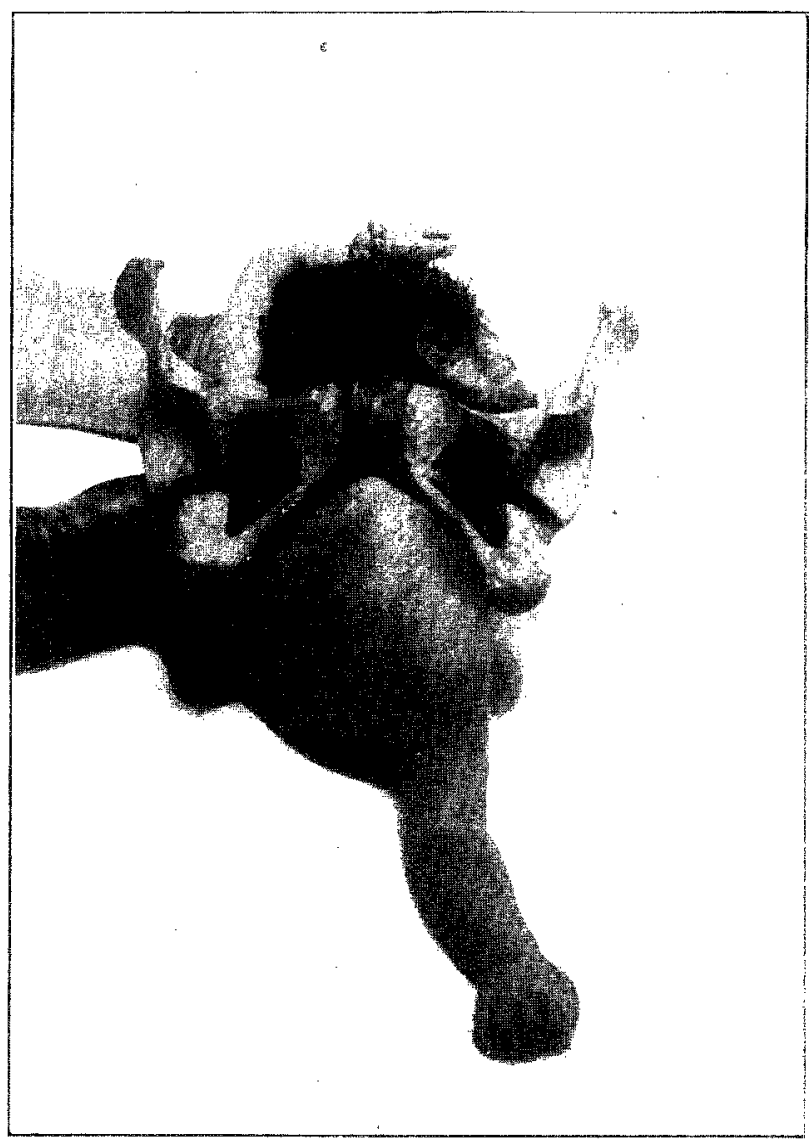

rig. 2.-Second step in Jouglas' mechanism of spontaneous evolution: stretching of neck, anl vance of trunk through pelvis, birth of shoulder.

Denman $^{2}$ in 1772 reported three cases of what he designated spontaneous evolution, and later claimed to have seen a total of thirty such cases, the baby being born alive in one instance. Payer ${ }^{1}$ interpreted Denman's report as specifying a mechanism in which the prolapsed arm receded, after which the breech descended. Denman's description of his observations is too vague and inaccurate to warrant its designation as an exact mechanism.

In 1819, Douglas ${ }^{3}$ described two types of mechanism by which 
a transversely presenting fetus might be born spontaneously. He referred to them as spontaneous evolution and spontaneous expulsion. What he mcans by the latter term is not quite clcar, but his deseription of the mechanism of spontaneous evolution is classic, with the result that this mode of delivery has come to be called "spontaneous evolution by Douglas' mechanism."

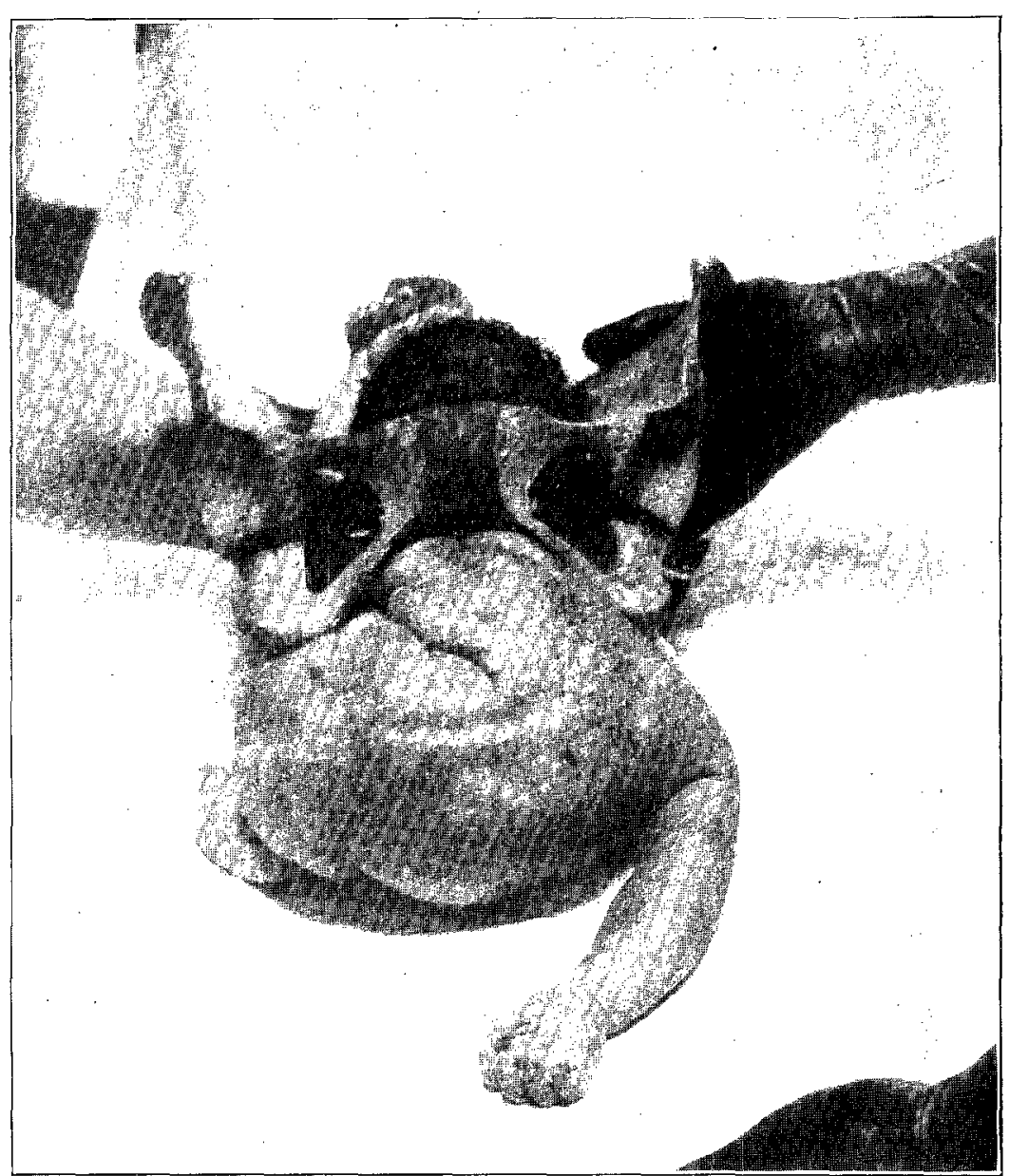

Fig. 3.-Third step in Douglas' mechanism of spontaneous evolution: birth of thorax and buttocks.

Stephenson ${ }^{4}$ has described two cases of spontaneous evolution oceurring in the Obstetric Service of the Johns Hopkins Hospital, and he is of the belief that this mode of delivery can take place only by Douglas' mechanism. The single case which I have to describe also followed the steps outlined by Douglas.

Description of Douglas' Mechanism.-Williams ${ }^{5}$ in his textbook gives a brief but comprehensive description of this mechanism, and I feel that it may properly be quoted verbatim. 
"In Douglas" mechanism, the first stage consists in the molding of the fetus and impaction of the shoulder with prolapse of the arm. Then, under the influence of strong uterine contractions, the child rotates about its vertical axis, so that one side of the head comes to lie over the horizontal ramus of the pubis with the breech in the region of the opposite sacro-iliac joint, while the neck subtends the inner surface of the symphysis pubis. Coincident with excessive stretehing of the neck, the prolapsed am contimues to descend until eventually the corresponding sioulder emerges under the pubic arch. The escape of the arm and shoulder affords room for the entrance of the rest of the body of the child into the pelvic cavity, and the lower side of the tholax, promptly followed by the breech, soon emerges from the vulva. Following the brecen the antorior side of the thorax and the remaining an are delivered, while the heal is born spontaneonsly, or is extracted manually, according to the exigencies of the case. In such cases the prolapsed arm is immensely swollen and a caput succedaneum develops over the presenting shoulder."

\section{INOIUENCE OF SPONTANEOUS EVOLUTION}

Transverse presentation occurs approximately once in two hundred pregnancies at or near term (Schroeder ${ }^{6}$ ). The rarity of spontaneous evolution will be appreciated, therefore, when it is pointed out that it occurs once in several hundred transverse presentations. Payer ${ }^{1}$ collected records of 34 cases in 468,557 births, whereas Stephenson reports it as having occurred at Johns Hopkins Hospital twice in 13,000 deliveries. It has been observed at the Western Pennsylvania Hospital just once in a total of about 3,500 deliveries at or near full term.

CASE ReponT.-The pationt, Mrs. S. B., a negress, aged twenty-nine years, pregnant for the eighth time. Her estimated date of confinement was August 22, 1920, but she passed this date, falling into labor two days later. It is of interest, since tilis was a twin pregnancy, that there is a family history of multiple pregnancies. Her husband has a brother and a sister who are twins, and the patient has two maternal aunts living, who are twins. The patient's other pregnancies and labors had been normal in every respect.

According to the attending physician, the delivery of the first twin was spontaneous after about four hours of labor, taking place at 12:05 P.M. on August 24, 1920. The membranes of the second twin ruptured about 3 P.M. and the right arm prolapsed through the vulva as the amniotic fluid drained away. The patient was being cared for under the most unsanitary and unygienic eircumstances and apparently there was little or no attempt at asepsis during the course of her treatment at home.

At 6 P.M. of the same day, the ambulance was called to take the patient to the Western Pennsylvania Hospital. Examination of the patient showed that the baby's entire right arm and shoulder were prolapsed through the vagina and vulva. The dorsal part of the riglit chest was also presenting, being visible as far as the inferior angle of the scapula. The baby was lying in a left acromion anterior position of a transverse presentation, and there was marked caput formation with its characteristic discoloration over the presenting part.

The ride to the Hospital was rather rough and the patient complained considerably during the trip of pains from which she was suffering. When placed upon the table in the Admission Room a distinet change was apparent from the findings as noted at the patient's house. The right arm and shoulder were prolapsed as described above, but in addition to this the right side of the baby's trunk down to and ineluding the right buttock was visible at the vulva. The body of the child was in a state of 
marked lateral flexion so that's some of the left side of its back could be seen. The right shoulder was tightly impinged under the symphysis pubis, and the shoulder and arm were a deep purple hue. No heart sounds could be heard through the baby's thorax.

Sterile gloves were drawn on, and the mere insertion of the fingers into the baby's right groin, with slight traction was sufficient to cause advance of the right buttock, followed immediately by the left buttock and then by both feet. The evolution

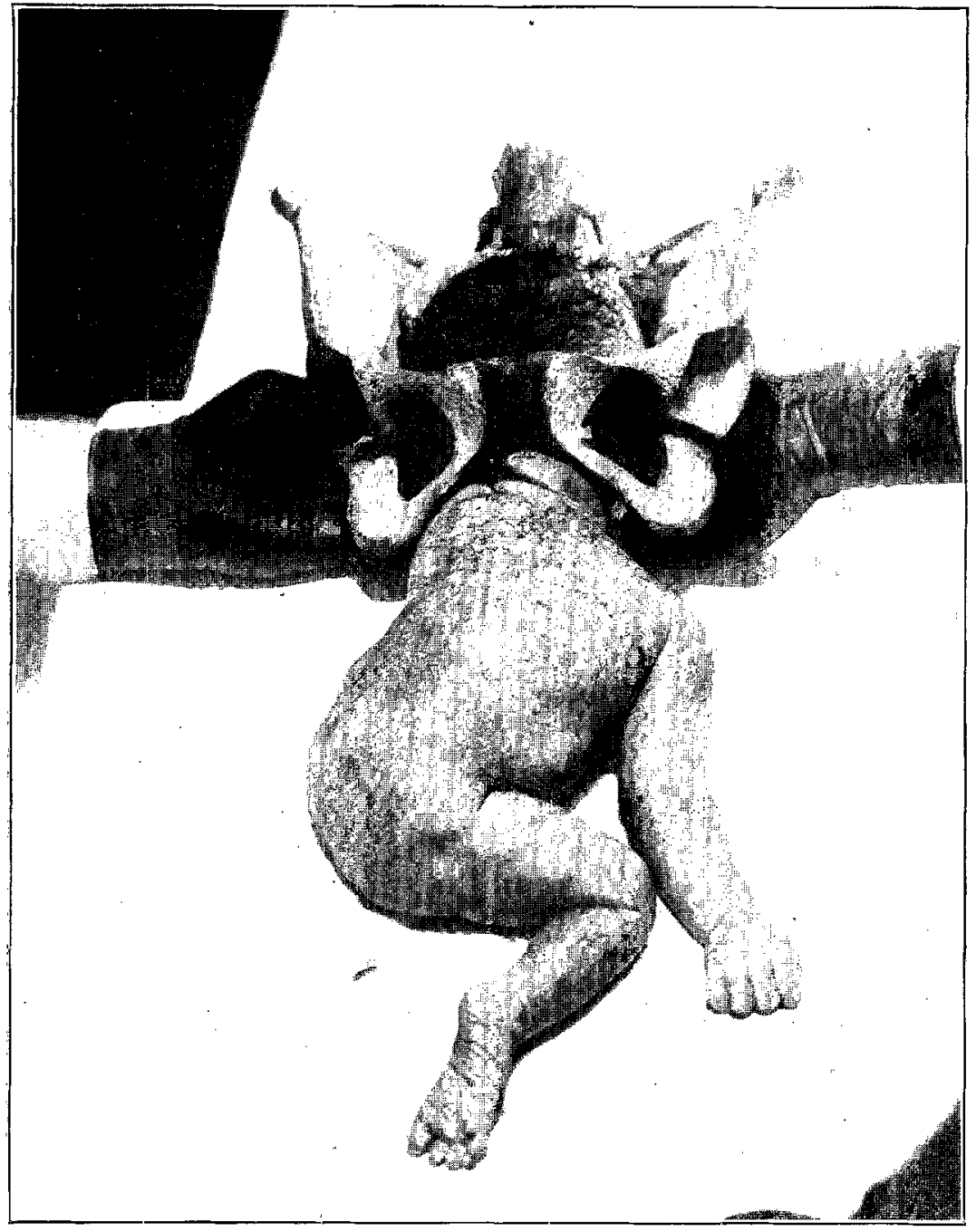

Fig. 4.-Fourth step in Douglas' mechanism of spontaneous evolution: evolution complete, birth procecding as in brecch presentation.

was spontaneous except for this slight interference or assistance. Delivery of the lead was easily effected by Mauriceau's maneuver, and it was moted at the time that the neck had been stretched to a considerable length. The infant was stillborn and weighed 2640 grams.

The mother's pelvic measurements were taken, and were those of a generally contracted pelvis of the rhachitic type. They were as follows: Inlet; interspinous 20.5 
cm., intercristate $23 \mathrm{~cm}$, Bitrochanteric $28.5 \mathrm{~cm}$, external conjugate $17.5 \mathrm{~cm}$, diagona! conjugate $11-\mathrm{cm}$, true conjugate $8.5 \mathrm{~cm}$, Outlet; anteroposterior $9.5 \mathrm{~cm}$., transverse $10 \mathrm{~cm}$., anterior sagittal $6 \mathrm{~cm}$, posterior sagittal $9 \mathrm{~cm}$.

A papier maché model pelvis, the measurements of which corresponded fairly closely to those of the patient was taken and the dead infant passed through it in duplication of the steps which had been observed. Several interesting photographs of the different steps in the mechanism were taken by Dr. J. F. MoCullough.

It is of interest that Herrgott ${ }^{\tau}$ has recently reported a case of spontaneous evolution with a history closely resembling that of this ease. It occurred in the second baby of a twin pregnancy, and the delivery was completed immediately after a long, rough ride to the hospital.

To summarize this subject as presented here, it may be said that spontaneous evolution is so rare that it cannot be relied upon to solve the problem of a fetus presenting transversely and impacted. The only accurately described mechanism of this delivery is that of Douglas, which was the type observed in this ease. The occurrence of evolution seems to be largely dependent upon several factors, such as maceration of the fetus, unless it be small by virtue of being one of twins, or premature. It is also essential that the neck stretch sufficiently so that the head can be above the ileopectineal line and the laterally flexed body within the birth canal.

\section{BIBLIOGRAPHY}

(1) Payer: Zur Lelre von der Selbstentwickelung, Volknam's Sammlung klin. Vorträge, 1901, No. 311. (2) Denman: Ouservaliuns to Prove that Delivery May be Effected by Spontaneous Evolution of the Child, London Med. Jour., 1785, v, 64. (3) Douglas: An Explanation of the Real Process of Spontaneons Evolution of the Fetus, ed. 2, Dublin, 1819. (4) Stephenson: The Mechanism of Labor in Spontaneous Evolution, Bull. Johns Hopkins Hosp., 1915, xxvi, 331. (5) Williams: Obstetrics, 1919, ed. 4, 869. (6) Schroeder, Olshausen und Veit: Lehrbuch der Geburtshülfe, 1899, ed. 13. (7) Herrgott: Un cas d Erolution Spontani, An», da gynee. ct d'obst., 1908, xiii, 193. 